\title{
Analysis of MOOC on Programming for IT Specialist Training
}

\author{
Sergii Sharov $^{1}$, Vira Kolmakova ${ }^{2}$, Tetiana Sharova ${ }^{3}$, Anatolii Pavlenko ${ }^{4}$ \\ ${ }^{1}$ Department of Computer Sciences, Dmytro Motornyi Tavria State Agrotechnological University, \\ 72312, Melitopol, Ukraine \\ ${ }^{2}$ Department of Computer Science, Information and Communication Technologies, Pavlo Tychyna Uman \\ State Pedagogical University, 20301, Uman, Ukraine \\ ${ }^{3}$ Department of Social Sciences and Humanities, Dmytro Motornyi Tavria State Agrotechnological \\ University, 72312, Melitopol, Ukraine \\ ${ }^{4}$ Department of Social Work, Khortytsia National Educational and Rehabilitation Academy, \\ 69017, Zaporizhzhia, Ukraine
}

\begin{abstract}
The article provides a quantitative analysis of online programming courses on such platforms as Alison, Udemy, Edx, Coursera, Udacity, Codecademy as of July 2021. The authors analyzed the number of courses that can be found either in thematic sections or by automatic keyword search. It was found that students can find 6,979 online programming courses on the analyzed platforms with the help of thematic sections. The Udemy platform provides the largest number of programming courses. Popular programming languages which have the largest number of online courses turned out to be Python, JavaScript and Java.
\end{abstract}

Keywords - MOOC, IT specialist, programming, high school, improvement of professional skills.

\section{Introduction}

The modern information society is characterized by an annual increase in information, rapid

DOI: 10.18421/TEM104-52

https://doi.org/10.18421/TEM104-52

Corresponding author: Sergii Sharov,

Department of Computer Sciences, Dmytro Motornyi Tavria State Agrotechnological University, Melitopol, Ukraine.

Email: segsharov@gmail.com

Received: 03 August 2021.

Revised: 05 November 2021.

Accepted: 11 November 2021.

Published: 26 November 2021.

(cc) BY-NC-ND (C) 2021 Sergii Sharov et al; published by UIKTEN. This work is licensed under the Creative Commons Attribution-NonCommercial-NoDerivs 4.0 License.

The article is published with Open Access at www.temjournal.com technological development, and introduction of information and communication technologies (ICT) in most areas of human activity. This trend has led to an increase in demand for IT specialists [1], in particular software engineers. This profession has recently become one of the most prestigious and highly paid ones [2]. Moreover, knowledge of IT and programming skills are part of digital competence which has now become a key competence for all people [3].

The demand for IT specialists in the labor market, variety of programming languages and software actualize the need for specialist training. Depending on the specialization, IT specialists must be able to develop different types of software, work with databases, administer operating systems and networks [4], provide information security, process graphic files, create video and 3D models, etc. Since the technological development of society is ongoing, IT specialists must constantly improve their skills and meet the requirements of the time.

IT specialist training is a complex and multifaceted task. It is solved through theoretical and practical training in various areas [5], focus on the most popular programming languages [6], practical orientation of the knowledge acquired. Studentcentered learning and specifics of the subject area have influenced the methods and teaching aids used to train future programmers. The effective means are the immediate assessment of the program code in automatic mode [7], the use of analytical projects [2], combination of related disciplines for the integrated development of professional competencies [4].

The introduction of ICT in the educational process allows us to diversify the process of future specialist training and to increase its efficiency. In order to train future software engineers, as well as anyone interested, various software solutions can be used: distance learning systems [3], educational 
programming resources [8], and massive open online courses (MOOC).

Recently, MOOC have become quite popular due to their availability and massive-scale nature. The effectiveness of MOOC to study programming has been proved by courses on various programming languages, such as Java [9], [10], Visual Basic [11], Haskell [12] and more. At the same time, there is a need for a more detailed quantitative analysis of available programming courses on various online platforms.

\section{Background Research}

\subsection{IT Specialist Training in the Field of Programming}

In the conditions when information society is rapidly developing, one can notice constant development of new software and hardware, as well as updating and modification of the existing ones. It is especially true for training future computer specialists who work directly with software and hardware. As a result, the requirements for the IT specialist training are constantly modified and supplemented.

Usually, software development is the responsibility of software engineers. They must be familiar with modern technologies and methods of processing, storage, protection, transmission of information [13], they must know modern programming languages and integrated development environments (IDE); they must be able to apply the acquired knowledge and skills to develop computer programs. One of the main requirements on the part of employers is knowledge of a specific language / environment / programming technology or a certain list of these components. The acquired experience and knowledge of specific software will increase programmers' productivity in the process of professional activity [1]; it will reduce the time and financial costs for their retraining.

Training of computer specialists, including future software engineers, has its own characteristics due to the availability of courses on software development and ICT use. Each programming language uses a certain programming technology (procedural, logical, functional, OOP); it has its own syntax which helps to implement the task that is set before the programmer [10]. This is especially true of the syntax of different programming languages, such as $\mathrm{C}++$, Pascal, Basic. At the same time, programmers must have the ability to create algorithm, divide the problem into several logical and consistent subtasks.

In addition to professional competencies, it is necessary for modern IT specialists to have welldeveloped soft skills. In particular, it is the ability to work in a team and perform project activities, the ability to analyze and synthesize the information obtained, independence, the ability to find necessary information in various sources. Now we can observe a trend when software development projects are not performed independently by only one programmer, but they appear as a result of teamwork. At the same time, project participants may be from different countries working outsourced. Therefore, welldeveloped communication skills [2], as well as social competence [14] are of particular importance for future IT specialists. They help to communicate effectively through social networks, instant messaging programs and more.

English is also highly important for software engineers. It is explained by the English syntax of programming languages which allow you to practically implement the algorithm using words and constructions which are intuitively understood. The work [15] identified a system of English-language training for future software engineers which involves the use of active teaching methods. In the process of communicative training, future IT specialists can form various communication strategies, as well as a glossary of IT and programming terminology.

Similar to any specialty, IT specialist training depends on the demand in the labor market, employers' requirements for future professionals [6]. Comprehensive theoretical and practical professional training, as well as formation of soft skills, can be obtained at a higher education institution. Moreover, training of future software engineers should be based on a competency-based approach, modern techniques and technological achievements. Only in this case, the IT specialist will be competitive. In this context the work [5] indicates the main points aimed at quality training of future software engineers: systematic review and updating of educational programs, taking into account the requirements of employers and other participants of the educational process; obtaining current and final information on student performance, making appropriate adjustments; improving the quality of teaching; providing students' practical training in real conditions at enterprises; advanced training of teachers; providing educational process with the necessary methodological, technological and other support.

Usually, training of a future specialist in computer science involves mastering professional disciplines, performing term papers, academic and on-the-job practices. At the end of the training, students have to defend their qualification work (project) and / or take the state final exam. These forms of state certification allow you to check the formation of professional and general competencies in accordance with the chosen specialty. 
Today, higher education institutions pay great attention to digitalization of the educational process. For this purpose, they use information environments to manage the educational process [16], as well as virtual social networks [17], augmented reality technologies [18], various electronic educational resources. The Learning Management System (LMS) and MOOC have proven themselves well for the professional training of future software engineers. Moreover, the correct selection of online courses will provide effective training for students with different levels of training [7], [12].

\subsection{Specific Features of Online Programming Courses}

MOOC is a modern electronic educational resource which supports the principles of massive-scale and open education which is based on network technologies and which allows you to learn independently and improve your skills. Compared to the LMS, which are designed to organize distance learning, they have more educational opportunities and are not tied to a specific educational institution. The advantages of the MOOC include:

- availability of a large number of online courses on various topics [19];

- support for multilingual interface;

- flexibility and individual working mode with educational material;

- the opportunity to join the courses created by teachers of leading educational institutions [9];

- availability of multimedia and interactive tools that allow students and teachers to work together [10];

- the opportunity to obtain a certificate after successful completion of the course.

Most MOOC are characterized by elements of the traditional education system, including lecture material, standardized control in the form of answers to testing tasks. They use objectivist-individual approach in learning which involves independent processing of information and high motivation to learn [20]. In addition, capabilities of Web 2.0 allow you to integrate video lectures, quizzes, surveys, graphic representation of the course dynamics, feedback, etc. into the MOOC.

Online programming courses can be studied by different categories of students:

- students who additionally receive information within a similar discipline;

- IT specialists who want to learn a new technology or programming language;

- teachers who want to get acquainted with leading teaching practices and technologies;

- any users who are interested in programming.
The specific features of online programming courses are explained by the specifics of software engineers' work, the need to form students' abstract and logical thinking, glossary of computing terms [11]. Knowledge of the syntax of specific programming languages, the principles of work with tool and application software is important in the study of programming. It is very good when online programming courses contain educational videos, examples of program code with an explanation of its work logic. In this case, students will be able to use it for producing software products in the future.

Similar to the content of any programming discipline, online courses should focus on the practical application of the knowledge acquired. As a result, they should include exercises for creating algorithms, programs or individual program blocks. The effectiveness of such online courses is proved by [10], [12]. In addition, there are corresponding voice agents [9] to provide interactivity and effective feedback for some online platforms.

One of the problematic issues to consider when studying programming with MOOC is the lack of direct contact with the teacher [12]. Due to the low level of understanding of the learning material, the high level of algorithmization and abstraction of certain topics, some novice programmers cannot complete the course on their own [9]. In this case, the teacher acts as an instructor who can explain the logic of the program code, who can advise on additional sources of information and show another solution to the problem, etc. On the other hand, some teachers have a low level of motivation and digital preparation for the use of MOOC in the educational process.

In today's pandemic environment when it is impossible to fully conduct face-to-face training, MOOC can be used effectively in blended learning [21]. In this case, learning materials, which are offered to students within the discipline, are supplemented with information from online courses. The basic learning material can be located in the LMS to ensure that all participants of the educational process registered in the system can get access to it. This form of the educational process organization will help to avoid certain shortcomings of the MOOC and improve the quality of learning.

\section{Methodology}

For the quantitative analysis of online programming courses, we analyzed six MOOC (Alison, Udemy, Edx, Coursera, Udacity, Codecademy) as of July 2021. Two methods were chosen to form the sample: a) search of online courses in thematic rubricators (catalogues that contain online courses on a particular topic); b) 
automatic search of online courses (names of programming languages were used as keywords).

The Alison online platform contains 160 courses in the thematic block "IT"-"Programming". Of these, 50 courses are designed to study programming languages and they have different levels of difficulty. Automatic search allowed us to find 79 online programming courses. With this method it was not possible to count the number of online courses to study $\mathrm{C}, \mathrm{C}++, \mathrm{C \#}$. This is due to the inclusion of these symbols in the names of non-programming courses. All courses are free and certified by the independent organization Continuing Professional Development. It confirms the high level of educational content which is presented in the online courses on this platform.

On the online platform Udemy, there are 6,759 courses to learn programming languages. They can be found in the thematic block "Development""Programming languages". Through this search you can find courses on 9 programming languages. Automatic search allowed us to find 93,428 online courses on 16 programming languages.

The Edx online platform contains 53 courses on programming languages. They can be found in such sections as "Computer Science" and "DataAnalisys \& Statistics". The sample of online courses which was found by automatic keyword search included 1,317 courses. This method did not let us count the number of online courses in the $\mathrm{C}, \mathrm{C}++$, and $\mathrm{R}$ programming languages due to the inclusion of these characters in the names of non-programming courses.

The analysis of programming languages on the Coursera platform was carried out in the section "Computer science" by means of automatic keyword search. Searching with subject headings demonstrated ambiguous results, so they were not taken into account. The names of the programming languages were used as keywords in the automatic search. This resource allows you to view 3,623 online programming courses. Due to the coincidences in the course names, it was not possible to perform an automatic search of the $\mathrm{C}$ and Go programming languages.

On the Codecademy platform, the sample of online courses for the quantitative analysis was made on the basis of the "Languages" section. There you can find 12 programming languages with two levels of difficulty ("Beginner friendly courses" and "Intermediate courses"). The total number of online programming courses was 117. Using automatic search by programming language names, we managed to find only 59 online courses on the Codecademy platform.

On the Udacity platform, the formation of a sample of online programming courses was made on the basis of the "Programming \& Development" section.
The total number of online courses on the platform is 8 courses, so their number was not taken into account in the quantitative analysis. For our study, the Udacity platform was useful for its specific features (availability of syllabuses and reviews of online courses).

\section{Result}

On the Alison platform, you can improve your qualification in different directions: IT, healthy lifestyle, business, marketing, personal development, education and science. Learning on the platform is free. However, the certificate is payable. There is a system of discounts (from 10\%) for different categories of users. The thematic block "IT" contains courses that allow users to learn about data safety, computer networks, information systems, engineering, programming, etc. In the thematic block "IT"-"Programming" users can learn nine programming languages: Java, JavaScript, Python, C, $\mathrm{C}++$, Perl, C\#, Swift, Ruby. Apart from thematic sections, the user can try an automatic keyword search of online courses. In addition, you can specify the selection criteria and choose duration (in hours), the type (certificate or diploma), level (beginner, intermediate, advanced), etc. The summarized data as for the number of online programming courses on the Alison platform are shown in Table 1.

Table 1. Number of online programming courses on the Alison platform

\begin{tabular}{|c|c|c|}
\hline \multirow{2}{*}{$\begin{array}{l}\text { Programming } \\
\text { language }\end{array}$} & \multicolumn{2}{|c|}{ Method of search } \\
\hline & Rubricator & $\begin{array}{c}\text { Automatic } \\
\text { search }\end{array}$ \\
\hline Java & 3 & 11 \\
\hline JavaScript & 4 & 13 \\
\hline Python & 12 & 40 \\
\hline $\mathrm{C}$ & 4 & - \\
\hline $\mathrm{C}++$ & 12 & - \\
\hline $\mathrm{C} \#$ & 9 & - \\
\hline Perl & 2 & 2 \\
\hline Swift & 2 & 9 \\
\hline Ruby & 2 & 4 \\
\hline Total & 50 & 79 \\
\hline
\end{tabular}

According to the presented data (see Table 1.), with the help of the rubricator, the user can access up to 50 online programming courses. The smallest number of courses is devoted to such programming languages as Perl, Swift, Ruby. They are represented by $2(4 \%)$ courses each. The most popular programming languages are Python and $\mathrm{C}++$ which have $12(24 \%)$ online courses each.

The sample, which was formed by an automatic search, includes 79 online programming courses. The least popular turned out to be the Perl programming language ( 2 courses, $2.5 \%$ ). The largest number of 
online courses is intended for learning the Python language (40 courses, $50.6 \%$ of the total number of online courses found with the automatic search).

On the Udemy platform, the thematic block "Development"-“Programming languages" contains online courses on Python, Java, C\#, React, C++, JavaScript, C, Spring, Go. Using the automatic search function for a specific programming language gives users a possibility to get more information about available online courses. With the help of the rubricator, seven more programming languages are added to the previously found programming languages, namely: Go, Kotlin, PHP, Swift, R, Ruby, Scala, Scratch. Quantitative indicators of online courses found on the Udemy platform are shown in Table 2.

Table 2. Number of online programming courses on the Udemy platform

\begin{tabular}{|c|c|c|}
\hline \multirow{2}{*}{$\begin{array}{c}\text { Programming } \\
\text { language }\end{array}$} & \multicolumn{2}{|c|}{ Method of search } \\
\hline & Rubricator & Automatic search \\
\hline Python & 2372 & $10000+$ \\
\hline Java & 1093 & $10000+$ \\
\hline $\mathrm{C \#}$ & 693 & 5850 \\
\hline React & 510 & 4824 \\
\hline $\mathrm{C}++$ & 393 & 2915 \\
\hline JavaScript & 1125 & $10000+$ \\
\hline $\mathrm{C}$ & 309 & $10000+$ \\
\hline Spring & 138 & 8337 \\
\hline Go & 126 & $10000+$ \\
\hline Kotlin & 0 & 1017 \\
\hline PHP & 0 & 6925 \\
\hline Swift & 0 & 1961 \\
\hline $\mathrm{R}$ & 0 & 5178 \\
\hline Ruby & 0 & 603 \\
\hline Scala & 0 & 541 \\
\hline Scratch & 0 & 5277 \\
\hline Total & 6759 & 93428 \\
\hline
\end{tabular}

Comparison of the obtained data (see Table 2.) allows us to draw a conclusion about the significant difference in the number of online courses found with the use of different methods. The section "Programming languages" contains 6,759 online courses on 9 programming languages. Most of online courses deal with such programming languages as Python (2,372 courses, $35.1 \%$ of the total number of online courses in the "Programming languages" section) and JavaScript (1,125 courses, 16.6\%). The smallest number of courses in the section deals with the Go language (126 courses, 1.9\%).

In its turn, the automatic search allows you to see 93,428 online courses on 16 programming languages. Searching for courses in automatic mode let us find 5 programming languages (Python, Java, JavaScript, C, Go) which have the maximum number of courses (more than 10,000). The smallest sample of online courses deals with the Scala programming language (541 courses).

To search for online programming courses on the Edx platform, you should go to the categories "Computer Science" and "DataAnalisys \& Statistics". According to these categories, 6 programming languages were identified (Python, Java, C, C++, Swift, R). You can review all the presented courses and clarify the following aspects: course duration, weekly workload for learning the programming language, the cost of the course and certificate, educational institution presenting the course, subject to which the course belongs, level of difficulty, language and type of the course.

Using automatic search you can see more online programming courses compared to the rubricator search. Additionally, courses on React, JavaScript, PHP, Ruby, Scratch, PyTorch, Arduino become available. The obtained quantitative indicators are shown in Table 3.

Table 3. Number of online programming courses on the Edx platform

\begin{tabular}{|c|c|c|}
\hline \multirow{2}{*}{$\begin{array}{c}\text { Programming } \\
\text { language }\end{array}$} & \multicolumn{2}{|c|}{ Method of search } \\
\hline & Rubricator & Automatic search \\
\hline Python & 27 & 112 \\
\hline Java & 4 & 583 \\
\hline $\mathrm{C}$ & 13 & - \\
\hline $\mathrm{C}++$ & 2 & - \\
\hline React & - & 179 \\
\hline JavaScript & - & 30 \\
\hline PHP & - & 6 \\
\hline Swift & 1 & 107 \\
\hline $\mathrm{R}$ & 6 & - \\
\hline Scala & - & 248 \\
\hline Ruby & - & 21 \\
\hline Scratch & - & 17 \\
\hline PyTorch & - & 4 \\
\hline Arduino & - & 10 \\
\hline Total & 53 & 1317 \\
\hline
\end{tabular}

Having analyzed the results of the tabular data (see Table 3.) we can state that according to the rubricator the smallest number of courses is devoted to the Swift programming language (1 course, $1.9 \%$ of the total number of courses in rubricators) and $\mathrm{C}++(2$ courses, 3.7\%). The most popular language appeared to be Python, 27 online courses were developed to learn it $(50.9 \%$ of the total number of courses found with the use of the rubricator). The second place in the number of online courses is taken by the $\mathrm{C}$ language (13 courses, 24.5\%).

The analysis of the courses received by means of the automatic search allowed us to show much higher indicators. Using this method we managed to find 1,317 programming courses. We found that when we automatically search for a specific programming language, the system reproduces the sample not only 
by the name, but it also takes into account the internal structure and content of the course. The course title does not always contain programming languages, so it is difficult to understand what the course includes. The most popular language on the Edx platform appeared to be Java with 583 online courses $(44.2 \%$ of the total number of programming courses found with automatic search). The least number of online courses deals with PyTorch (4 courses) and PHP (6 courses).

If users want to learn programming with the Coursera platform, they should focus on the "Computer Science" section. It contains 5 subcategories "Software-development", "Mobile and web development", etc. Each subcategory presents the most popular topics, including programming languages. However, the list of programming languages is missing. Therefore, it is not possible to correlate programming languages with particular thematic sections.

The Coursera platform has a developed function for a keyword search of online courses. To simplify the search, you can filter courses by the following criteria: language, level, duration, topic, skills, collaboration, and learning product. The summarized data on the number of online courses on the Coursera platform is shown in Table 4.
Table 4. Number of online programming courses on the Coursera platform

\begin{tabular}{|c|c|c|}
\hline \multirow{2}{*}{$\begin{array}{c}\text { Programming } \\
\text { language }\end{array}$} & \multicolumn{2}{|c|}{ Method of search } \\
\hline & $\begin{array}{c}\text { Automatic } \\
\text { search }\end{array}$ & $\begin{array}{l}\text { Percentage of the total } \\
\text { number of courses }\end{array}$ \\
\hline Java & 1427 & 39,4 \\
\hline Python & 938 & 25,9 \\
\hline PHP & 42 & 1,2 \\
\hline Scala & 414 & 11,4 \\
\hline JavaScript & 271 & 7,5 \\
\hline $\mathrm{C}++$ & 112 & 3,1 \\
\hline $\mathrm{CH}$ & 100 & 2,7 \\
\hline Swift & 203 & 5,6 \\
\hline Ruby & 71 & 2 \\
\hline PyTorch & 27 & 0,7 \\
\hline Arduino & 18 & 0,5 \\
\hline Total & 3623 & \\
\hline
\end{tabular}

As we can see from Table 4., the Coursera platform mostly deals with Java $(1,427$ courses, $39.4 \%$ of the total number of online programming courses) and Python (938 courses, 25.9\%). The least number of the courses on the platform deals with Arduino (18 courses, 0.5\%) and PyTorch (27 courses, 7.4\%). Since Arduino is promising for robotics, we hope that the number of courses on this programming language will increase significantly in the future. Most courses are free. However, the certificate must be paid for.

The online platform Codecademy contains programming courses in the section "Catalog" "Languages". There are 12 programming languages (HTML, CSS, Python, JavaScript, Java, etc.). Courses are designed for two levels of training (Beginner and Intermediate). Also, keyword search of online courses is available for users. The obtained quantitative indicators are shown in Table 5.

Table 5. Number of online programming courses on the Codecademy platform

\begin{tabular}{|c|c|c|c|c|}
\hline \multirow{3}{*}{$\begin{array}{l}\text { Programming } \\
\text { language }\end{array}$} & \multicolumn{4}{|c|}{ Method of search } \\
\hline & \multicolumn{3}{|c|}{ Rubricator } & \multirow{2}{*}{ Automatic search } \\
\hline & Beginner & Intermediate & Total & \\
\hline HTML \& CSS & 5 & 8 & 13 & 10 \\
\hline Python & 12 & 26 & 38 & 10 \\
\hline JavaScript & 10 & 24 & 34 & 10 \\
\hline Java & 10 & 3 & 13 & 10 \\
\hline Ruby & 1 & 2 & 3 & 3 \\
\hline $\mathrm{C}++$ & 1 & 0 & 1 & 1 \\
\hline $\mathrm{R}$ & 2 & 4 & 6 & 6 \\
\hline $\mathrm{CH}$ & 1 & 2 & 3 & 3 \\
\hline PHP & 0 & 1 & 1 & 1 \\
\hline Go & 1 & 0 & 1 & 1 \\
\hline Swift & 2 & 1 & 3 & 3 \\
\hline Kotlin & 1 & 0 & 1 & 1 \\
\hline Total & 46 & 71 & 117 & 59 \\
\hline
\end{tabular}


According to the data obtained, 117 online programming courses are available for the future programmer. Most of the online courses in the "Languages" deal with the Python language (38 courses, $32.56 \%$ of the total number of programming courses). JavaScript (34 courses, 29\%) takes the second place in the number of online courses. There is only one course for the C++, PHP, Go, Kotlin programming languages.

With the help of automatic online search, the platform displays only 59 online courses. Analysis of the number of courses obtained through different methods revealed a discrepancy of 58 courses. The most popular programming languages appeared to be HTML \& CSS, Python, JavaScript, Java; there are 10 courses for each one of them.

Some of the considered online courses are partially paid. There are courses where only a few classes are paid and the course itself is free. For students there is a system of discounts on the cost of courses (up to $35 \%$ ). However, such a discount is active after confirmation of the student status and is valid for no more than 4 years. To receive bonuses in the form of a reduced cost for an online course, you must annually confirm your student status.

On the Udacity platform, you can search for online courses with the "Programming \& Development" section. There are courses on Python, JavaScript, Java, C++, Swift, Xcode, Kotlin, Android Basics and more. You can also use the search bar and filter function (program type, skill level, course duration, skills). A small number of programming courses (one course for each programming language) was found on this platform, so we did not consider them in the overall analysis.
A specific feature of the Udacity platform is the display of reviews of the online course. The number of reviews ranges from 105 to 3,114 depending on the programming language. If the course has not been completed by users, it does not contain any reviews (Table 6.).

Table 6. Number of online programming courses on the Udacity platform

\begin{tabular}{|l|c|c|}
\hline $\begin{array}{c}\text { Programming } \\
\text { language }\end{array}$ & $\begin{array}{c}\text { Number of } \\
\text { courses }\end{array}$ & $\begin{array}{c}\text { Number of } \\
\text { course reviews }\end{array}$ \\
\hline Python & 1 & 951 \\
\hline Java & 1 & New course \\
\hline $\begin{array}{l}\text { Front End Web } \\
\text { Developer }\end{array}$ & 1 & 986 \\
\hline Swift Xcode & 1 & 835 \\
\hline C++ & 1 & New course \\
\hline JavaScript & 1 & 105 \\
\hline Kotlin & 1 & 196 \\
\hline Android Basics & 1 & 3114 \\
\hline \multicolumn{1}{|c|}{ Total } & 8 & 6187 \\
\hline
\end{tabular}

Another advantage of this resource is the availability of a syllabus which describes the course program in detail. Such information is greatly important for users who will be able to optimally plan their own learning process. Detailed information about the course is contained in a file together with the specification of terms, number of classes, course teachers, etc.

The summarized data on the number of online programming courses on different platforms which can be found with the help of rubricators is shown in Table 7.

Table 7. Number of online programming courses displayed in rubricators

\begin{tabular}{|c|c|c|c|c|c|}
\hline \multirow{2}{*}{$\begin{array}{l}\text { Programming } \\
\text { language }\end{array}$} & \multicolumn{4}{|c|}{ MOOC } & \multirow{2}{*}{ Number } \\
\hline & Alison & Udemy & Edx & Codecademy & \\
\hline Java & 3 & 1093 & 4 & 13 & 1113 \\
\hline JavaScript & 4 & 1125 & - & 34 & 1163 \\
\hline Python & 12 & 2372 & 27 & 38 & 2449 \\
\hline $\mathrm{C}$ & 4 & 309 & 13 & - & 326 \\
\hline $\mathrm{C}++$ & 12 & 393 & 2 & 1 & 408 \\
\hline $\mathrm{CH}$ & 9 & 693 & - & 3 & 705 \\
\hline Perl & 2 & - & - & - & 2 \\
\hline Swift & 2 & - & 1 & 3 & 6 \\
\hline Ruby & 2 & - & - & 3 & 5 \\
\hline React & - & 510 & - & - & 510 \\
\hline Spring Framework & - & 138 & - & - & 138 \\
\hline Go & - & 126 & - & 1 & 127 \\
\hline Kotlin & & - & - & 1 & 1 \\
\hline PHP & - & - & - & 1 & 1 \\
\hline $\mathrm{R}$ & - & - & 6 & 6 & 12 \\
\hline HTML \& CSS & - & - & - & 13 & 13 \\
\hline Total & 50 & 6759 & 53 & 117 & 6979 \\
\hline
\end{tabular}


According to Table 7., you can find 6,979 online courses with the help of rubricators on four platforms. Most courses are presented on the Udemy online platform (6,759 online courses, 96.8\%).

On all the considered platforms there are online courses on programming languages such as Java, Python, $\mathrm{C}++$. Their total number is 3,970 online courses which is $56.9 \%$ of the total number of online programming courses. The leaders in popularity appeared to be such programming languages as Python $(2,449$ courses, $35 \%$ of the total number of online programming courses), JavaScript $(1,163$ courses, 16,6\%) and Java (1,113 courses, 15.9\%). The least popular programming languages appeared to be Perl (2 courses), Kotlin and PHP (1 course each). Regarding the PHP web-programming language, the obtained data require additional analysis. Besides, some programming languages (Scala, Scratch, PyTorch, Arduino) could not be found with the help of the rubricator.
Based on the analysis of the total number of online courses for each programming language which are displayed in the thematic sections we can talk about the popularity of the programming language on different MOOC (Figure 1.).

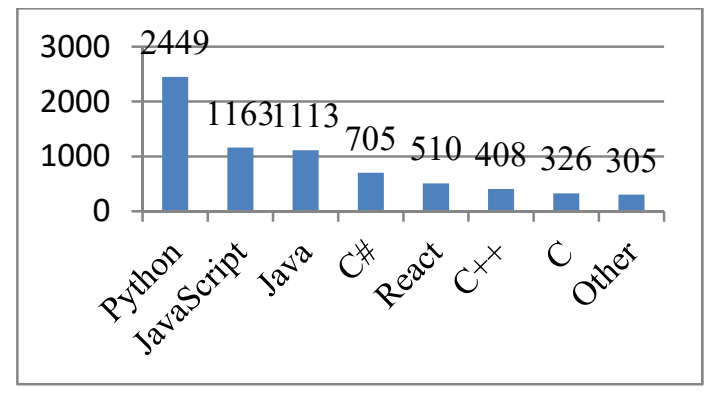

Figure 1. Ranking of the programming language popularity by the number of online courses

The summarized data on the number of online programming courses on different platforms which can be found by automatic keyword search is shown in Table 8.

Table 8. Number of online programming courses using auto search

\begin{tabular}{|c|c|c|c|c|c|c|}
\hline \multirow{2}{*}{$\begin{array}{c}\text { Programming } \\
\text { language }\end{array}$} & \multicolumn{5}{|c|}{ MOOC } & \multirow{2}{*}{ Number } \\
\cline { 2 - 6 } & Alison & Udemy & Edx & Coursera & Codecademy & \\
\hline Java & 11 & $10000+$ & 583 & 1427 & 10 & 12031 \\
\hline JavaScript & 13 & $10000+$ & 30 & 271 & 10 & 10324 \\
\hline Python & 40 & $10000+$ & 112 & 938 & 10 & 11100 \\
\hline C & - & $10000+$ & - & - & - & 10000 \\
\hline C++ & - & 2915 & - & 112 & 1 & 3028 \\
\hline C\# & - & 5850 & - & 100 & 3 & 5953 \\
\hline Perl & 2 & - & - & - & - & 2 \\
\hline Swift & 9 & 1961 & 107 & 203 & 3 & 2283 \\
\hline Ruby & 4 & 603 & 21 & 71 & 3 & 702 \\
\hline React & - & 4824 & 179 & - & - & 5003 \\
\hline Spring & - & 8337 & - & - & - & 8337 \\
\hline Go & - & $10000+$ & - & - & 1 & 10001 \\
\hline Kotlin & - & 1017 & - & - & 1 & 1018 \\
\hline PHP & - & 6925 & 6 & 42 & 1 & 6974 \\
\hline Scala & & 541 & 248 & 414 & - & 1203 \\
\hline R & - & 5178 & - & - & 6 & 5184 \\
\hline Scratch & - & 5277 & 17 & - & - & 5294 \\
\hline PyTorch & - & - & 4 & 27 & - & 31 \\
\hline Arduino & - & - & 10 & 18 & - & 28 \\
\hline HTML \& CSS & - & - & - & - & 10 & 10 \\
\hline Total & 79 & 93428 & 1317 & 3623 & 59 & 98506 \\
\hline
\end{tabular}

The analysis of Table 8 . revealed a much larger number $(98,506)$ of online programming courses compared to the number of online courses found with the help of the rubricator (see Table 7.).

On all the considered platforms there are online courses on the following programming languages: Java, JavaScript, Python, Swift, Ruby. Their total number is 36,440 online courses which is $37 \%$ of the total number of online programming courses. The most popular languages found with keyword search appeared to be Java $(12,031$ courses, $12.2 \%$ of the total number of courses), Python $(11,100$ courses, $11.2 \%)$ and JavaScript (10,324 courses, 10.4\%).

\section{Discussion}

A large number of online programming courses presented on various MOOC platforms will improve the skills of not only a beginner, but also an experienced programmer. Criteria for selecting an online programming course can be: popularity of the programming language, previous work experience, 
requirements of the software customer, teacher's instructions. When choosing the first programming language to study, you should consider the compatibility of syntax with popular programming languages, the clarity of program code, free compiler or IDE [6], availability of free sources providing reference information (guides, forums, etc.).

Each online programming course requires a certain level of training (understanding the principles of algorithms, ICT skills, at least a minimum level of English). Out of doubt, the initial skills of working with IT and programming languages are formed at school. The basic course of programming will allow students to form mathematical and digital competence [3], they will show them the attractiveness of being an IT specialist, and they will prepare them for using ICT in a more active way. At the same time, students who have demonstrated high abilities for programming could consider the future career well in advance [8].

In our study, we used two ways to find online programming courses. The first method involved the analysis of online courses by thematic sections. In this case, the exact number of courses related to a specific programming language was found. The second method meant using automatic keyword search of online courses. Programming languages were used as keywords. This method allowed us to get a much larger number of courses. However, the disadvantage of this method is that programming courses are not always included in the sample. It could include courses on office programs, public speaking, English, etc. We witnessed this situation with such programming languages whose names consist of 1-2 letters (C, R, Go, etc.). In this case, the user will have to browse the names of online courses and choose the right one.

Regarding the organization of the educational process at university, it is recommended to combine the capabilities of the MOOC and traditional learning. The effectiveness of such a combination is mentioned in [11], [12], [22]. In the conditions of blended learning, students have the opportunity to communicate with the teacher, use printed and electronic sources of information, increase cognitive interest, as well as to optimize the amount of educational material and time for its study. All this, in turn, will provide simultaneous training of students with different levels of training [7] and will positively affect their academic success [21]. Additionally, to provide feedback between the teacher and students, you can use software solutions that allow you to check and compile the program code [10], provide recommendations in natural language in real time using conversational agents [9] or bots [23].
It should be noted that the content of training provided for future software engineers in the educational institution should be periodically improved. First of all, it concerns the revision of educational programs and curricula [5] in accordance with the technological development of society, popularity of programming languages [6], industry demands and requirements for future professionals in the labor market [13]. Similarly, working programmers also need to improve their programming and teamwork skills [1]. Hence, it will have a positive effect on the demand for the specialists and their salary.

\section{Conclusion}

Thus, mastering programming skills and improving knowledge of IT is one of the key competencies of modern man. Training of future IT specialists, in particular software engineers, involves the acquisition of theoretical knowledge, formation of professional competencies, practical orientation of educational activities. Such training has specific features related to the need to develop algorithmic thinking, to master various information technologies and tool environments, to know the syntax of programming languages and the rules of writing a program code.

Online education remains an effective means of acquiring knowledge and developing competencies in a distant way. It can be applied to all users who have access to the Internet and desire to learn. One of the effective means of online education is the MOOC which provides access to a large array of information on various topics.

Quantitative analysis of online programming courses presented on such online platforms as Alison, Udemy, Edx, Coursera, Codecademy allowed us to identify the most useful MOOC for programmers. A comparison of the quantitative indicators which were obtained with the two methods used to search for online courses revealed significant differences in the number of online programming courses that were found. We found 6,979 online programming courses in the thematic sections (rubricators) of the considered online platforms. At the same time, we managed to find 98,506 online courses using automatic keyword search of online courses.

Online courses on 21 programming languages were analyzed on different platforms. The maximum number of programming courses is presented on the Udemy online platform $(6,759$ online courses, $96.8 \%$ of the total number of online courses displayed in the rubricators). The Udacity online platform has the fewest number of programming courses ( 8 courses). It was analyzed to demonstrate its key features. In 
particular, it concerns the availability of syllabuses and reviews of each online programming course.

The analysis of the total number of online courses on all platforms revealed that the largest number of courses in the rubricators are presented by such programming languages as Python $(2,449$ courses, $35 \%$ of the total number of online programming courses), JavaScript (1,163 courses, $16.6 \%)$ and Java $(1,113$ courses, $15.9 \%)$. If you use automatic search of online courses, you see that the largest number of online courses are devoted to such programming languages as Java (12,031 courses, $12.2 \%$ of the total number of courses), Python (11,100 courses, 11.2\%) and JavaScript (10,324 courses, 10, 4\%).

In the future, it is planned to analyze the capabilities of the MOOC for software engineers' training in various fields (development of desktop and mobile applications, web-programming, etc.).

\section{References}

[1]. Saputra, R., \& Napitupulu, T. A. (2014). Factors Affecting Programmer's Performance on Web-Based Programming. Journal of Theoretical \& Applied Information Technology, 63(2).

[2]. Donina, I. A. (2020). Analytical projects as an innovative means in training of programmers. In EpSBS (pp. 506-513), European Publisher. https://doi.org/10.15405/epsbs.2020.08.02.66

[3]. Shokaliuk, S. V., Bohunenko, Y. Y., Lovianova, I. V., \& Shyshkina, M. P. (2020). Technologies of distance learning for programming basics lessons on the principles of integrated development of key competences. Proceedings of the 7th Workshop on Cloud Technologies in Education (CTE 2019), Kryvyi Rih, Ukraine.

[4]. Vavrecková, S. (2020). The Combination of Skills Training for IT Administrators and Programmers. In ISSEP (CEURWS Volume) (pp. 152-159).

[5]. Kruhlyk, V. (2018). Quality assurance system for professional training of future programmers in the Ukrainian higher educational institutions. Engineering and Educational Technologies, 6(4), 58-65. https://doi.org/10.30929/2307-9770.2018.06.04.06

[6]. Prokop, Y., Trofimenko, E., Loginova, N., Zadereyko, A., \& Gerganov, M. (2019, July). Multivariate analysis when choosing the first programming language studied in universities. In 2019 IEEE 2nd Ukraine Conference on Electrical and Computer Engineering (UKRCON) (pp. 1224-1228). IEEE. https://doi.org/10.1109/UKRCON.2019.8879810

[7]. Skalka, J., \& et al. (2021). Conceptual framework for programming skills development based on microlearning and automated source code evaluation in virtual learning environment. Sustainability, 13(6), 1-30. https://doi.org/10.3390/su13063293

[8]. Çetinkaya, A., \& Baykan, Ö. K. (2020). Prediction of middle school students' programming talent using artificial neural networks. Engineering Science and Technology, an International Journal, 23(6), 13011307. https://doi.org/10.1016/j.jestch.2020.07.005
[9]. Catalán, A. C., González-Castro, N., Delgado, K. C., Alario-Hoyos, C., \& Muñoz-Merino, P. J. (2021). Conversational agent for supporting learners on a MOOC on programming with Java. Computer Science and Information Systems, (00), 20-20. https://doi.org/10.2298/csis200731020c

[10]. Király, S., Nehéz, K., \& Hornyák, O. (2017). Some aspects of grading Java code submissions in MOOCs. Research in Learning Technology, 25. https://doi.org/10.25304/rlt.v25.1945

[11]. X. Zhang, X. Huang, F. Wang and X. Cao.,(2018). "Research on MOOC-based blended learning of programming language course", DEStech Trans. Social Sci. Edu. Human Sci., pp. 586-591.

[12]. Dale, V. H., \& Singer, J. (2019). Learner experiences of a blended course incorporating a MOOC on Haskell functional programming. Research in Learning Technology, 27. https://doi.org/10.25304/rlt.v27.2248

[13]. Farmonovich, T. M. (2021). Formation Of Professional Communicative Competence Of Programmers Them In A Competitive Environment. Psychology and Education Journal, 58(2), 1327-1330. https://doi.org/10.17762/pae.v58i2.2278

[14]. Sharov, S., Vorovka, M., Sharova, T., \& Zemlianska, A. (2021). The Impact of Social Networks on the Development of Students' Social Competence. International Journal of Engineering Pedagogy, 11(3). https://doi.org/10.3991/IJEP.V11I3.20491

[15]. Mykytenko, N., Rozhak, N., \& Semeriak, I. (2019). Teaching Communication Strategies to the Computer Programming Students. Advanced Education, 6(12), 49-54. https://doi.org/10.20535/2410-8286.167148

[16]. Morozov, A. V., \& Vakaliuk, T. A. (2021, March). An electronic environment of higher education institution (on the example of Zhytomyr Polytechnic State University). In Journal of Physics: Conference Series (Vol. 1840, No. 1, p. 012061). IOP Publishing. https://doi.org/10.1088/1742-6596/1840/1/012061

[17]. Bijari, B., Javadinia, S. A., Erfanian, M., Abedini, M., \& Abassi, A. (2013). The impact of virtual social networks on students' academic achievement in Birjand University of Medical Sciences in East Iran. Procedia-Social and Behavioral Sciences, 83, 103-106. https://doi.org/10.1016/j.sbspro.2013.06.020

[18]. Abidin, Z. Z., \& Zawawi, M. A. A. (2020). OOPAR: Learn Object Oriented Programming Using Augmented Reality. International Journal of Multimedia and Recent Innovation, 2(1), 60-75. https://doi.org/10.36079/lamintang.ijmari-0201.83

[19]. Sharov S., Zemlianskyi A., Sharova T., \& Viktor H. (2021). Ukrainian MOOC: Quantitative and Thematic Analysis of Online Courses. International Journal on Advanced Science Engineering Information Technology, 11(3), 1143-1149. https://doi.org/10.18517/ijaseit.11.3.13705

[20]. Toven-Lindsey, B., Rhoads, R. A., \& Lozano, J. B. (2015). Virtually unlimited classrooms: Pedagogical practices in massive open online courses. The internet and higher education, 24, 1-12.

https://doi.org/10.1016/j.iheduc.2014.07.001 
TEM Journal. Volume 10, Issue 4, Pages 1884-1894, ISSN 2217-8309, DOI: 10.18421/TEM104-52, November 2021.

[21]. Larionova, V., Brown, K., Bystrova, T., \& Sinitsyn, E. (2018). Russian perspectives of online learning technologies in higher education: An empirical study of a MOOC. Research in comparative and international education, 13(1), 70-91. https://doi.org/10.1177/1745499918763420

[22]. Vihavainen, A., Luukkainen, M., \& Kurhila, J. (2012, October). Multi-faceted support for MOOC in programming. In Proceedings of the 13th annual conference on Information technology education (pp. 171-176). https://doi.org/10.1145/2380552.2380603
[23]. Dominic, J., Ritter, C., \& Rodeghero, P. (2020, June). Onboarding Bot for Newcomers to Software Engineering. In Proceedings of the International Conference on Software and System Processes (pp. 91-94). https://doi.org/10.1145/3379177.3388901 